\title{
"Sociedade Civil Global": Agentes Não Estatais e Espaço de Interação na Sociedade Política*
}

Victor Coutinho Lage**

Wa segunda metade do século XX, as ciências sociais iniciaram um período de reflexão acerca dos princípios epistemológicos, ontológicos e metodológicos nos quais se calcavam as predominantes concepções positivistas, empiricistas e quantitativas (KELLNER, 1990). A alegada "crise das ciências sociais" (KELLNER, 1990) reverberou nos mais diversos campos, entre eles as Relações Interna-

\footnotetext{
* Artigo recebido em 30 de outubro de 2012 e aprovado para publicação em 30 de novembro de 2012. Agradeço a Viviane Vieira Gomide e Fernando Neves da Costa Maia pelos valiosos comentários ao texto. Agradecimentos adicionais devem ser feitos a João Pontes Nogueira e R. B. J. Walker, além de Nicholas Onuf, que continuamente influenciam e encorajam parte das reflexões aqui expressas.

** Doutorando em Relações Internacionais pelo programa de pós-graduação do Instituto de Relações Internacionais da Pontifícia Universidade Católica do Rio de Janeiro (IRI/PUC-Rio). E-mail: victorcoutinholage@yahoo.com.br.
}

CONTEXTO INTERNACIONAL Rio de Janeiro, vol. 34, noำ 1, janeiro/junho 2012, p. 151-188. 


\section{Victor Coutinho Lage}

cionais e a Ciência Política. Quando se trata das primeiras, percebe-se que, desde as décadas de 1970 e, especialmente, 1980, essas reflexões vêm provocando amplo impacto na produção de conhecimento. Nesse quadro, houve o surgimento ou a difusão de temas como os da globalização, da governança global, da sociedade civil global; e de teorias denominadas "críticas", "pós-positivistas", "pós-modernas". 1 Este texto pretende discutir o conceito de "sociedade civil global", 2 em torno do qual giram inúmeras polêmicas, divergências, apologias, expectativas e contestações (MUNCK, 2006); para tanto, propõe uma abordagem que se erija a partir de um diálogo entre parte do que se convencionou chamar de "construtivismo" em Relações Internacionais ${ }^{3}$ e alguns elementos da obra do pensador francês Michel Foucault (1926-1984). Conceitos-chave em ciências sociais (e, em menor medida, em ciências naturais) tendem a ser essencialmente contestáveis, uma vez que são organizadores e constitutivos de uma realidade socialmente construída, e não externa, fixa ou metafísica. Assim entende-se aqui o termo "sociedade civil global".

Quando se é lançado a essa tarefa, o primeiro percalço a se apresentar é de ordem conceitual, residindo na própria definição de "sociedade civil global", a qual abrange, a um só tempo, dimensões normativas, descritivas e analíticas (MUNCK, 2002). Munck (2002) e Kaldor (2003) enfatizam um requisito fundamental para o entendimento do termo, a saber, a rejeição de qualquer abordagem teleológica que estipule uma trajetória inexorável sob os auspícios de uma sociedade civil global una. Por vezes, o conceito padece de duas mazelas, apontadas por Munck (2002): (1) adquire tamanha amplitude que, por pretender explicar tudo, atinge o paradoxo de nada elucidar, em virtude de sua debilidade fundacional - é o que o autor chamou de "inflação conceitual” (MUNCK, 2002, p. 352); ${ }^{4}$ e/ou (2) é acometido pelo "presentismo", ou seja, uma sensação de se estar diante de algo sem precedentes, postura que corre o sério risco de obliterar a pers- 
pectiva histórica na qual se insere o fenômeno - não se trata de negar o novo, e sim de evitar a negligência a algum sentido de continuidade que possa existir entre o contemporâneo e o passado. A perspectiva aqui trabalhada ainda busca evitar outra debilidade comum. Nogueira (2000) salienta que a literatura acerca da sociedade civil global com frequência recai ou em utopias apologéticas inspiradas por um "cosmopolitanismo liberal ingênuo"5 (NOGUEIRA, 2000, p. 408) ou em visões que chegam a aceitar a globalização, porém perduram na crença da centralidade do Estado nas relações internacionais e/ou no que Ashley (1988) chama de "discurso da problemática da anarquia" (NOGUEIRA, 2000, p. 227, ênfase minha); 6 outros autores convergem com Yunker (2004), classificando de "mito disfuncional" a sociedade civil global, uma vez que é pautada na ideia, que consideram ilusória, de poder haver governança efetiva sem um governo efetivo.

Em face de tais controvérsias, uma atitude inicial adequada parece ser a de evitar oposições binárias e abordagens que rotulem a sociedade civil global como essencialmente boa ou má, terceiro-mundista ou eurocêntrica, progressista ou perversa - rejeitar, em suma, maniqueísmos e definições carregadas de conteúdos propagandísticos ou ideológicos não problematizados. "Espaço" deve ser entendido de modo amplo, desde seu aspecto material e geográfico de "lugar" até sua característica social e política, na condição de contexto de interação produtor de sentidos, identidades, problematizações, diálogos, políticas públicas; ainda, deve-se entender a relação entre práticas espaciais e projetos políticos (NOGUEIRA, 2000); de acordo com Giddens (1991, p. 27), "lugar" se refere a localidade, cenário físico, situado geograficamente, ao passo que "espaço", a relações entre “"ausentes', localmente distantes de qualquer situação dada ou interação face a face". 7 


\section{Victor Coutinho Lage}

A conceituação de qualquer palavra envolve: (1) o reconhecimento da inexistência de neutralidade política e normativa do conceito; (2) a relação do conceito com o contexto no qual foi formulado; e (3) a concepção processual da definição, ou seja, a noção do conhecimento como sempre reconstruído e em movimento. ${ }^{8}$ A definição é muito mais do que um formalismo ou convencionalismo teórico; os conceitos são vivos: atribuem sentido a parte do mundo e agem no próprio contexto ao qual pertencem (BARTELSON, 2000).

O conceito de "sociedade civil global", conforme será trabalhado adiante, traz à tona os limites para se pensar em uma sociedade civil para além do Estado. Tais limites podem ser entendidos a partir de duas interpretações para a noção de "além do Estado". Em primeiro lugar, problematiza-se a centralidade do Estado nas Relações Internacionais, de forma que a "sociedade civil global" é entendida sob a ótica de um conjunto de agentes e um espaço de interação social que convive com o Estado, sem que isso signifique a obsolescência ou a superação deste. Nesse sentido, "além do Estado" consiste em uma ampliação dos fenômenos concebíveis através do estudo das Relações Internacionais. Em segundo lugar, abordam-se os limites para se entender a formação de uma sociedade civil que transpasse as fronteiras do Estado, que não se confine a elas, ou seja, que estejam para "além do Estado". O adjetivo "global" nesse caso pretende exatamente suscitar essa reflexão, e não indicar que tal sociedade tem um potencial inclusivo global para a política contemporânea. A rigor, como será visto ao longo do texto, a sociedade civil global pode ser interpretada como um conjunto de agentes e um espaço de interação que expressam distribuições desiguais de benefícios e privilégios na dinâmica de poder da sociedade política.

Algumas ressalvas se fazem necessárias. Primeiramente, o objetivo do texto é dialogar diretamente com as Relações Internacionais, de modo que a maior parte dos textos trabalhados a seguir expressa ou 
influencia a discussão do conceito de "sociedade civil global" nesse campo de estudo. Não faz parte do escopo da discussão aqui proposta abordar os engajamentos com o conceito em outros campos, como estudos culturais, antropologia ou mesmo ciência política. A segunda ressalva, ligada à primeira, é que não é o foco do texto propor uma história conceitual da sociedade civil global, a despeito de sua extrema relevância. A opção aqui é lidar com intervenções contemporâneas no tema, embora não se deva perder de vista que o uso do termo é, em si mesmo, já marcado pela sua história. Em terceiro lugar, a despeito do foco na dimensão espacial da sociedade civil global, o aprofundamento da discussão requer que se considere a dimensão temporal do mesmo; ou seja, pensar uma sociedade para além do Estado implica pensar rearticulações espaço-temporais que acompanham a interação dos agentes. Esse texto se limita, no entanto, a considerações acerca das implicações espaciais, deixando para estudos ulteriores o aprofundamento supracitado.

Diante disso, reitera-se que o texto irá considerar a sociedade civil global, por um lado, como um espaço de interação agente-estrutura ${ }^{9}$ ou, de forma mais precisa, interação de agentes diferenciados em sua capacidade de atuação e institucionalização de propostas com as instituições e estruturas construídas socialmente; e, por outro lado, como um conjunto abrangente no qual se inserem agentes não estatais de objetivos, valores, modos de atuação e formas de organização múltiplos. ${ }^{10}$ A fim de explorar essa dupla dimensão do conceito de "sociedade civil global" e dialogar diretamente com as Relações Internacionais, este texto se divide em três seções seguidas por uma breve conclusão. Na próxima, dedicar-se-á à discussão acerca da primeira parte da definição proposta acima, ou seja, da sociedade civil global como espaço de interação agente-estrutura; na seção subsequente, o foco é a segunda parte e, dessa feita, o conceito se refere aos agentes não estatais de escopo global. A terceira seção funde as duas partes supracitadas. 


\section{"Sociedade Civil Global" como Espaço de Interação: Para Além do Interestatal}

De início, há que se discutir um problema ontológico: o adjetivo "global", a princípio, não apresentaria nenhum ganho à "sociedade civil"; ou, de modo mais preciso, não teria qualquer impacto para a produção de conhecimento, comparado ao termo "sociedade civil". O ponto a ser problematizado aqui se liga às fronteiras ontológicas ${ }^{11}$ dos campos de Relações Internacionais e de Ciência Política, na dissolução da premissa de "analogia doméstica" (KRATOCHWIL, 1989). Tal premissa é tomada convencionalmente como fundamento da separação entre o interno e o internacional, de maneira que as anárquicas relações internacionais fossem conceitualizadas em sua condição de oposição frontal à hierárquica política doméstica, como discute Walker (1993). Onuf (1989), um dos expoentes do construtivismo em Relações Internacionais, rejeita a divisão disciplinar entre Ciência Política e Relações Internacionais - divisão esta de longa tradição nos estudos políticos - em favor da concepção de "sociedade política". Cabe, então, uma digressão no texto, a fim de se compreender melhor a noção de sociedade política com a qual se opera; para tanto, a trajetória proposta tem como origem Onuf e, como ponto de chegada, Foucault, passando por Guzzini. Com isso, propõem-se linhas gerais para um diálogo entre construtivismo e Foucault, que possibilite uma interpretação alternativa do contexto em que se inserem os limites de uma sociedade civil para além do Estado, adjetivada aqui pelo termo "global". 12

\section{Sociedade política e condições de governo}

A sociedade política é concebida por Onuf (1989) por intermédio do conceito de "condições de governo" (conditions of rule) ${ }^{13}$ Nessa perspectiva, o "governo" remete a um arranjo de regras, formais e in- 
formais, que geram expectativas acerca do comportamento dos agentes em interação, sejam estatais, sejam não estatais. A sociedade política se define pelas relações mantidas por regras e geradoras de modos de governo que não incidem necessariamente sobre territórios fixos ou, ao menos, seus contextos não são mutuamente exclusivos (RUGGIE, 1998). Essa definição permite conceber a "sociedade civil global" como parte de uma sociedade política, com suas condições de governo específicas e distribuiçõos de benefícios peculiares, sempre em interação com outros contextos.

O construtivismo de Onuf (1989), ${ }^{14}$ não obstante sua contribuição para a reconsideração do problema ontológico das Relações Internacionais (a divisão interno-internacional), carece de uma maior reflexão acerca da problemática do poder. $\mathrm{O}$ autor tem por estratégia evitar o uso do termo "poder", em razão das ambiguidades históricas e teóricas que nota entre os estudiosos (ONUF, 1989, p. 237-238). ${ }^{15} \mathrm{~A}$ despeito dessa posição e seguindo os propósitos deste artigo, a problemática do poder é precípua para o entendimento da sociedade política e da relação desta com a sociedade civil global; para tanto, Guzzini e Foucault contribuem de maneira considerável com o construtivismo. $^{16}$

Guzzini empenha-se na inclusão do conceito de poder na literatura construtivista. A saliência disso, segundo o autor, é a conexão entre a atribuição de poder e a "arte do possível", isto é, a noção de que as coisas poderiam ser feitas diferentemente - uma visão cujo efeito é politizar as questões sociais, trazendo à tona a necessidade de justificações políticas para os cursos de ação adotados ou preconizados. É um processo frontalmente oposto a quaisquer argumentos defensores da neutralidade conceitual. Conjecturar sobre alternativas ao status quo é, no sentido mais amplo, questionar os efeitos vigentes de poder, quando não, de maneira mais penetrante, propor uma movimentação crítica que estimule a mudança social, em prol de um novo contexto de interação e, por conseguinte, novas condições de governo. 


\section{Victor Coutinho Lage}

Na reconstrução operada pelo autor, o construtivismo é uma metateoria caracterizada (1) pela sensibilidade à distinção entre ação e observação, assim como à relação entre ambas, teorizadas em termos de poder; ${ }^{17}$ (2) pela adoção epistemológica da premissa de construção social do sentido e do conhecimento; e (3) pela ontologia defensora da construção social da realidade (GUZZINI, 2003). ${ }^{18}$ Não é uma negação da existência de um mundo externo ao pensamento, e sim da possibilidade de concebê-lo como um conjunto de fenômenos e objetos autoconstituídos, de maneira independente das práticas discursivas e das interpretações socialmente sustentadas. ${ }^{19}$ O conceito de poder, de acordo com Guzzini (2000), apresenta-se na condição de elo entre a construção social do sentido e do conhecimento e a da realidade; ou entre o conhecimento, a ordem social e a ação coletiva.

Nas palavras de Guzzini (2005, p. 511), “ser ‘político’ significa ser potencialmente alterável; isto é, algo que não seja natural, criado por Deus, e sim algo que tenha o potencial de ser influenciado pela agência" 20 em interação mutuamente constitutiva com a estrutura e as instituições, em um processo político constante e perpassado por relações de poder. $\mathrm{O}$ construtivismo "entende o poder tanto como agencial quanto como intersubjetivo (incluindo poder não intencional e impessoal)", sendo "mais sintonizado a questões de processos de legitimação 'naturalizados' e abertos ou tomados como dado"21 (GUZZINI, 2005, p. 507-508). ${ }^{22}$ Guzzini (2005) defende uma ampliação e uma simultânea contração da política, entendida por ele como a "arte do possível": a ampliação remete à expansão dos tipos de agentes fazedores de política, não mais exclusividade do Estado; a contração, à restrição de capacidades de controle dos Estados e de outros atores internacionais, em virtude, exatamente, da ampliação supramencionada. Percebe-se um nítido distanciamento de Guzzini, assim como de Onuf, das abordagens estadocêntricas tradicionais em Relações Internacionais e, por conseguinte, da distinção ontológica entre o interno e o externo, por muito tempo consubstanciada e 
não problematizada no campo. Percebe-se, ademais, uma potencial aproximação entre o construtivismo e Foucault, pautada por um corolário fundamental: política e poder são inseparáveis. ${ }^{23}$

Foucault foi proponente de uma analítica do poder inspirada em Nietzsche, ${ }^{24}$ perpassada por estratégias retóricas textuais intrigantes. Uma das grandes contribuições do pensador francês foi questionar a visão jurídico-soberana do poder como algo repressivo e negativo, em prol de uma abordagem atenta aos efeitos positivos do poder, à maneira como ele produz saber, discurso, objetos, verdade - à rede produtiva, em suma, do que permeia a sociedade e faz com que não haja verdade sem poder ou fora dele (FOUCAULT, 2007a). De fato, é exatamente pelo fato de o poder não ser somente negativo ou repressor que pode ter tamanha força, capacidade produtiva; sendo assim, é vão o empreendimento da busca da Verdade por detrás do poder, haja vista que este e aquela não se distinguem. O poder não é passível de ser posse de alguém, não há algo como uma transferência do mesmo entre os agentes; é ação, exercício, relação de força, fabricante de verdade (FOUCAULT, 2005; 2007a), daí a relevância de uma analítica cuja meta não é defini-lo, e sim entender como se dá sua atuação.

Segundo o autor, "cada sociedade tem seu regime de verdade, sua "política geral' de verdade" (FOUCAULT, 2007a, p. 12) e, com a finalidade de analisá-la, deve-se rejeitar a busca por uma origem ou identidade primeira, a partir da qual tudo se resumiria a deturpações da verdade, em favor do restabelecimento do "jogo causal das dominações", dos "sistemas de submissão" (FOUCAULT, 2007a, p. 23). As regras, nessa perspectiva, são estipuladoras de um incessante jogo de dominação social, sem distinção entre a guerra e a renúncia a ela, tida como a paz. É a essa concepção que se associa a inversão do teorema de Clausewitz: a guerra não é a política por outros meios, e sim a política é a guerra por outros meios (FOUCAULT, 2005; 2007a). A genealogia se instaura a partir do instante em que se elimine "a tirania dos discursos englobantes com suas hierarquias e os privilégios da 


\section{Victor Coutinho Lage}

vanguarda teórica" (FOUCAULT, 2007a, p. 171). Um desses discursos, pode-se afirmar, é o da soberania, transformado em emblema maior das Relações Internacionais e de sua separação disciplinar da Ciência Política. Isso não significa eliminar o Estado, porém problematizar seus mínimos e capilares efeitos, táticas, realizações, assim como ampliar o espaço da política, abarcando saberes diversos, resistentes, contestadores e não estatais.

Cinco precauções metodológicas do autor ilustram com nitidez a concepção do poder e de como operar sua analítica: (1) afastar-se do sentido jurídico-soberano que lhe é atribuído, em direção à dominação que coloca em prática; (2) entender a circulação do saber como fruto dos efeitos de poder; (3) abordá-lo como uma cadeia ou rede, e não como propriedade; (4) pincelar sua ascendência dos níveis mais baixos e locais aos mais gerais, das microrrelações e dos feixes de poder ao ponto mais alto; e, finalmente, (5) estudar sua face externa, ou seja, a das práticas reais e efetivas nas quais é viável enxergar seu exercício. O poder, então, é mais bem compreendido pelos seus caracteres disciplinar e normalizador: a norma se aplica ao corpo a ser disciplinado (poder disciplinar) e à população a ser regulamentada (biopoder) (FOUCAULT, 2005).

Cumpre ressaltar que, para Foucault (2007a, p. 241), não é uma questão de aceitar e se submeter passivamente aos efeitos positivos do poder, afinal "a partir do momento em que há uma relação de poder, há uma possibilidade de resistência. Jamais somos aprisionados pelo poder: podemos sempre modificar sua dominação em condições determinadas e segundo uma estratégia precisa". ${ }^{25}$ Em outro texto, as lutas de resistência são classificadas como: (1) transversais, isto é, não limitadas a um país ou a uma forma de governo particular, não obstante serem mais comuns em determinados lugares; (2) possuindo como alvo os efeitos do poder; (3) imediatas, uma vez estarem apontadas para as instâncias de poder próximas e não visarem a um futuro idealizado ou distante; (4) questionadoras do status do indiví- 
duo, preconizando o direito de ser diferente e criticando qualquer tentativa de ruptura do elo entre indivíduos; (5) contrárias ao privilégio do conhecimento e às imposições sobre as pessoas; e, por fïm, (6) identitárias, buscando a autodefinição e a construção das identidades (FOUCAULT, 1982). ${ }^{26}$

A microfísica de poder é "posta em jogo pelos aparelhos e instituições, mas cujo campo de validade se coloca de algum modo entre esses grandes funcionamentos e os próprios corpos com sua materialidade e suas forças" (FOUCAULT, 1987, p. 26). Dessa forma, é possível ler o espaço do poder como sendo no interstício entre as condições de governo vigentes e os agentes nelas inseridos. Nessa leitura, os efeitos de poder se assemelhariam às regras do construtivismo de Onuf (1989): ambos (regras e poder) estariam manipulando recursos e, com isso, distribuindo benefícios de maneira diferenciada na sociedade. As regras são intermediárias na relação entre agentes e estruturas e/ou instituições, havendo uma relação intrínseca entre regras e recursos. Ao passo que o construtivismo, conforme aqui apresentado, explicita os caminhos pelos quais as regras se institucionalizam e constituem condições de governo, Foucault se foca nos efeitos que as regras e os recursos, sob a rubrica do poder, geram na sociedade política:

[...] o poder não para de questionar, de nos questionar; não para de inquirir, de registrar; ele institucionaliza a busca da verdade, ele a profissionaliza, ele a recompensa. Temos de produzir a verdade como, afinal de contas, temos de produzir as riquezas, e temos de produzir a verdade para poder produzir as riquezas. E, de outro lado, somos igualmente submetidos à verdade, no sentido de que a verdade é a norma; é o discurso verdadeiro que, ao menos em parte, decide; ele veicula, ele próprio propulsa os efeitos do poder (FOUCAULT, 2005, p. 29). 


\section{Victor Coutinho Lage}

A citação acima parece fortalecer a possibilidade de diálogo entre Foucault e o construtivismo de Onuf e, em especial, a reconstrução de Guzzini. A produção da verdade pode ser relacionada à construção da regra e à mudança social, pontos de foco compartilhados pelos autores; ademais, a relação entre a verdade ou a regra, por um lado, e as riquezas ou os recursos, por outro, possibilitam compreender o elo entre a materialidade e a construção social da realidade.

Por um lado, o poder é sempre indiscreto, está por toda parte e sempre em alerta, "não deixa nenhuma parte às escuras e controla continuamente os mesmos que estão encarregados de controlar; e absolutamente discreto, pois funciona permanentemente e em grande parte em silêncio" (FOUCAULT, 1987, p. 148); é uma situação estratégica de uma sociedade (DREYFUS; RABINOW, 1995). Por outro lado, as regras estão, também, por toda parte, e, junto com os recursos, ${ }^{27}$ constituem o aparato social de distribuição de benefícios e mesmo de possibilidade de resistência, tendo em vista a capacidade que os agentes possuem de proferir atos de fala e, potencialmente, transformá-los em regras ou instituições, o que alteraria as condições de governo ou, para retornar a Foucault (1987; 2007b), a economia política da verdade. Tanto essa concepção de poder como a de regras conduzem a uma observação de Guzzini (2005) feita acima, qual seja, a das simultâneas ampliação e contração da política, afinal poder e regras estão por toda parte e, em razão disso, limitam a atuação dos agentes.

Em termos de filosofia da ciência, tanto o construtivismo quanto a analítica do poder de Foucault são pós-metafísicos, opositores das noções de neutralidade axiológica, de separação sujeito-objeto, do postulado da verdade como correspondência, da linguagem como reflexo do mundo externo e do puro realismo filosófico. Há uma correspondência ontológica entre ambos: a distinção interno-externo se dilui na visão geral da política e do poder por toda a sociedade, em desconsideração a fronteiras ontológicas, pensadas, então, como 
fronteiras onto-políticas. Há, ainda, uma aproximação epistemológica, na medida em que se defendem as viradas linguística, sociológica e interpretativa das ciências sociais. Foucault rejeita a noção de um sujeito que movimente a história e, diferente de Nietzsche, não funda as práticas sociais e a moralidade em agentes tomados individualmente, e sim em uma estratégia sem estrategistas (DREYFUS; RABINOW, 1995); o potencial efeito colateral disso é a negligência da agência, algo que suscita polêmica entre os leitores do autor - vale lembrar, Foucault, assim como o construtivismo, nega a precedência ontológica do sujeito em relação à sociedade, o que não deve levar à conclusão de que a agência se oblitera nessas abordagens.

\section{A sociedade civil global na sociedade política}

Percorrida a trajetória de Onuf a Foucault, com ponto intermediário em Guzzini, faz-se uma conclusão acerca da discussão. O objetivo dos parágrafos anteriores foi de estabelecer um diálogo entre construtivismo e Foucault, a fim de se compreender onde se situa o espaço de atuação da sociedade civil global. Reitera-se: a sociedade política se conforma pela mútua constituição de agentes e estruturas, um processo eminentemente político, gerador e influenciado por efeitos de poder. Assim, o agente, imerso em condições de governo peculiares, atua com o objetivo de transformar suas demandas em regras e, quiçá, em instituições. É uma relação sem precedência ontológica ou causal, afinal o agente altera as condições de governo, as quais, por seu turno, limitam a capacidade de agência de cada um, em uma cadeia de funcionamento sem ponto de origem e sem qualquer teleologia predeterminada. As relações sociais são políticas e perpassadas por efeitos de poder, à medida que este é produtor de verdades, assim como dos próprios agentes, de uma política geral de poder-saber, de uma norma social; a sociedade é uma situação estratégica de posicionamento dos agentes, em uma distribuição de benefícios capaz de ser 


\section{Victor Coutinho Lage}

alterada pela agência. Nesse panorama, o poder não se limita a espaços geográficos determinados a priori - dilui, em suma, tanto a distinção ontológica entre o interno e o internacional, como também arruína a exclusividade do Estado como locus de enunciação e de emanação de um poder soberano. A política é ampliada e contraída: o espaço não mais é internacional, no sentido de ser ocupado apenas por Estados, e sim mais abrangente, daí a ampliação da política; concomitantemente a isso, o que antes era, por um lado, um domínio de livre arbítrio do Estado, de sua soberania interna, e, por outro, de não ingerência (ou não intervenção) entre os agentes, de sua soberania externa, passa a se caracterizar por regras e normas que instituem limites à liberdade e à prerrogativa de ação política, daí sua contração.

Tornar a existência coletiva humana uma concatenação de esferas mutuamente exclusivas de pensamento e ação incapacita o conhecimento de problematizar o cerne dos efeitos produtivos do poder (CHANDHOKE, 2002). A sociedade civil global, de acordo com a primeira parte da definição inicial, somente pode ser entendida através de sua inserção nessa sociedade política. É o espaço - imbricado com outros espaços e contextos - de atuação dos agentes não estatais, o espaço de resistência, de movimentação social, de lutas por mudança. Isso abre novas oportunidades, destrona a primazia do internacional e concebe as relações sociais e políticas como abrangentes quanto aos agentes nelas envolvidos - e complexas, no que tange as meticulosidades do poder e de seus efeitos e da maneira como a resistência deve ser erigida. Essa resistência e a mudança social a ela associada não podem ser interpretadas, nessa perspectiva, como garantidoras de progresso social e político. Abordar o espaço da sociedade civil global sob o prisma de uma sociedade política não diz nada acerca dos resultados da dinâmica social, não prescreve ou preconiza a resistência como local de progresso, decadência ou continuidade, em contraponto a um poder nefasto. Em suma, não se trata aqui de uma perspectiva denuncista dos efeitos de poder que veria a resistência 
como saída das condições de governo da sociedade política. A seguir, passa-se à segunda parte da definição de sociedade civil global.

\section{"Sociedade Civil Global" como Agentes Não Estatais: Para Além das Fronteiras do Estado}

Nos parágrafos seguintes, a sociedade civil global será abordada como o conjunto de agentes não estatais atuantes na sociedade política, com vistas a institucionalizar suas demandas ou a estimular, propor ou gerar mudanças de regra e políticas. Os elementos desse conjunto são movimentos sociais, nacionalistas, fundamentalistas, organizações não governamentais, corporações transnacionais, instituições financeiras, grupos de cidadãos, grupos criminosos e terroristas, comunidades epistêmicas; uma gama extensa de agentes que, conquanto suas abismais diferenças de funcionamento, organização, origem e princípios, "pensam e agem globalmente"28 (RUGGIE, 2004, p. 510) via interconexões em uma rede de mobilização que mescla relacionamentos de presença e ausência (AXFORD, 2004). Para alguns, a sociedade civil global deve ser um meio de questionamento da legitimidade do Estado (BAKER, 2002) ou de desafio à primazia do mesmo (ATAMAN, 2003); outros estudiosos abordá-la-ão como substitutos ou auxiliares no desempenho das tarefas cuja responsabilidade sempre foi imputada ao Estado; outros, é possível aduzir, interpretá-la-ão como perigosos agentes de subversão da ordem social, relacionando-a às redes terroristas e ao crime organizado.

De acordo com Kaldor (2003, p. 2), a mudança fundamental para a emergência da sociedade civil global foi ocasionada quando "o fim da Guerra Fria e a crescente interconexão global dirimiram a distinção territorial entre sociedades 'civis' e 'não civis', entre o ocidente 'democrático' e o oriente e o sul 'não democráticos' e questionaram o Estado guerreiro centralizado tradicional", 29 favorecidos pelos de- 


\section{Victor Coutinho Lage}

senvolvimentos tecnológicos e pelas crescentes legitimidade e autoridade moral que seus agentes adquirem com o passar do tempo (CHANDHOKE, 2002). Atentar-se ao rompimento da rigidez de fronteiras ontológicas é bem diferente de postular o fim do Estado, o fim do território ou de fazer qualquer constatação ou profecia apocalíptica referente ao agente estatal e a suas propriedades e prerrogativas. O próprio adjetivo "global" não pode conduzir ao equívoco do estabelecimento de uma nova oposição, dessa feita com o nível "local", mas sim ser um termo a explicitar o engajamento com a literatura acadêmica a ele referida e contribuir para o entendimento das especificidades do contexto contemporâneo, para o qual "global" se apresenta como a mais recente formulação. ${ }^{30}$

O fim da Guerra Fria trouxe, na opinião de Kaldor (2003), dois desdobramentos significativos para o conceito de sociedade civil global. Em primeiro lugar, a preocupação com autonomia pessoal, auto-organização e espaço privado se alastrou não apenas pela Europa Oriental, como também por outras partes do mundo. Já nos anos 1960 e 1970, nos Estados Unidos e na Europa Ocidental, os direitos civis, o feminismo e o meio ambiente haviam sido temas em torno dos quais movimentos sociais se organizaram. Na década seguinte, o termo "sociedade civil" ganhou força na parte leste da Europa e, paralelamente, em outras regiões do globo, como a América Latina, em resposta a uma percepção de intrusão excessiva do Estado no cotidiano das pessoas. Em segundo lugar, somada ao fim do conflito bipolar, a interconexão global crescente transformou as fronteiras de atuação da sociedade civil.

Kaldor (2003) e Bowden (2006) narram a perspectiva histórica da sociedade civil de maneira semelhante, salvo pelo fato de o segundo traçar sua origem em Aristóteles (colocado no posto de precursor da ideia), enquanto, para a primeira, a origem do termo sociedade civil societas civilis - remete aos pensadores dos séculos XVII e XVIII, como Hobbes e Locke, os quais a opunham ao estado de natureza, in- 
distinta da existência do Estado e em oposição às sociedades não civis e à guerra. Bartelson (2006), por sua vez, defende que societas civilis é um conceito anterior ao Estado moderno, em oposição às cidades-Estados, unidades políticas predominantes na época. A despeito dessa divergência, os estudiosos do conceito concordam com a visão de separação da sociedade civil em relação à autoridade política central, não importa de que período se esteja falando ou de que tipo de autoridade - Estado moderno ou cidade-Estado. ${ }^{31}$

Com Hegel, a sociedade civil fora abordada como a arena produzida historicamente pela emergência do capitalismo e, pela primeira vez, contrastada com o Estado (HABERMAS, 2002a; KALDOR, 2003; BOWDEN, 2006). Desde o fim do século XVIII, com a emergência do Estado moderno, a distinção não mais se dava frente ao estado de natureza, e sim ao próprio Estado; era o surgimento dos sujeitos cidadãos. ${ }^{32}$ Em períodos mais recentes, Kaldor (2003) seleciona três versões do conceito: a ativista, relacionada à atuação de oposição aos governos praticada na Europa Central, nos anos 1970 e 1980, cujo objetivo era redistribuir o poder do Estado; a neoliberal, cuja definição aponta para um terceiro setor, o qual teria como meta substituir algumas funções do Estado por meio de organizações não governamentais (ONGs); por fim, a versão pós-moderna rompe com qualquer visão universalista, em prol de um princípio de tolerância, pluralismo, contestação, de identidades nacionais e religiosas. A sociedade civil global, na definição aqui avançada, é o conjunto de agentes pertencentes a todas as três últimas versões acima (ativista, neoliberal e pós-moderna), não importa quais sejam os formatos que tenham tomado atualmente e os rótulos que se lhe atribuam.

Muitas das abordagens históricas ligavam a sociedade civil a dimensões normativas: para uns, era um estágio de evolução em direção ao comunismo (Marx); para outros, representava o próprio telos da humanidade, seja na realização do mundo moderno (Hegel), seja no "fim da história" (Fukuyama) (KALDOR, 2003). A história narra, 


\section{Victor Coutinho Lage}

por um lado, aqueles que defendem que a sociedade civil representa o atingimento da liberdade privada e, por outro, aqueles que a remetem à liberdade coletiva. A diversidade de interpretações ao longo do tempo serve para demonstrar um modo pertinente de fuga do "presentismo", vício apontado anteriormente. Vale lembrar que o conceito esteve historicamente ligado ao Estado e, portanto, às fronteiras estatais, as quais o confinavam ao ambiente interno. $\mathrm{O}$ aparecimento da ideia de sociedade civil "global" é fruto da problematização do confinamento ao interno - tema discutido na parte anterior do texto e ao qual se voltará adiante. Por ora, convém somente apontar as transformações históricas do conceito e sua abrangência: confinado ao interno, o termo apenas remeteria a agentes não estatais domésticos, atuantes na sociedade política doméstica. Os anos 1970 e 1980, nesse panorama, representam um deslocamento conceitual, uma reconstrução ontológica e política - uma crítica, em suma, às limitações fronteiriças impostas aos agentes da sociedade civil. Não se está defendendo com isso que a sociedade civil global é um fenômeno novo; o escopo deste texto pretende apenas apontar elementos da literatura contemporânea, especialmente de Relações Internacionais, a partir dos quais se pode problematizar a separação entre o doméstico e o internacional, daí a importância de se conceber a sociedade civil global pelo prisma da sociedade política.

Persiste, entretanto, em alguma medida, uma "inflação conceitual". Como foi dito, sob o rótulo de "sociedade civil global" estão os mais variados agentes não estatais, com objetivos, valores, modos de organização e meios de atuação diversos, quando não opostos entre si, e origens variadas, malgrado sua concentração geográfica no norte ocidental ser marcante. A opção mais adequada parece ser a conservação da heterogeneidade do rótulo, focando-se, contudo, na relação peculiar mantida entre os agentes não estatais e a sociedade política, conforme abordada acima. O corolário disso é a junção das duas partes da definição de sociedade civil global. 
Apesar de múltiplas dinâmicas e origens dos processos e atividades terem sido formadoras da sociedade civil global (KEANE, 2001), Kaldor (2003) estipula o começo de sua robustez no instante em que a paz e os direitos humanos foram interpretados como inseparáveis, por volta de meados da década de 1970, em várias partes do mundo. Na América Latina, a sociedade civil começava a se movimentar contra as ditaduras instauradas nos países. Na Europa Central, o reflexo disso foi atestado nos novos movimentos sociais e grupos de cidadãos, com ligações transeuropeias e, por vezes, globais. Outra fonte de novas ideias foi a Europa Ocidental, lugar de proliferação do movimento de paz, em resposta ao desenvolvimento de armas nucleares; houve uma ênfase no papel dos cidadãos em escala transnacional. Com o tempo, os movimentos sociais europeus iniciaram o estabelecimento de um diálogo, por meio das novas tecnologias de informação, de seminários e de novos meios de transporte. Os debates operaram como um aprendizado social, de influência em muitos pensadores e indivíduos em geral; a concatenação dos posicionamentos combinava reflexões acerca dos impactos da globalização, da difusão da democracia para o leste da Europa, da ampliação da capacidade de agência das pessoas e de maior participação e deliberação nos processos decisórios. Consolidou-se uma nova versão da sociedade civil, fruto de uma mudança no caráter da autoridade política e de uma expressão de aspirações mais audaciosas por parte de agentes excluídos da dinâmica política pelos blocos do sistema bipolar. O argumento de Kaldor (2003) é: desde a proliferação dos movimentos sociais dos anos 1970 e 1980 e com a crescente interconexão global e comunicação dialógica dos agentes não estatais, consubstanciou-se uma sociedade civil global, cujos participantes cada vez mais se desatavam dos limites geográficos estatais, conformando redes globais de cooperação, troca de ideias e atuação.

Nessa dinâmica, grupos, movimentos e redes passaram a negociar, a fazer política em uma escala para além das fronteiras estatais ou inte- 


\section{Victor Coutinho Lage}

restatais. O efeito disso foi apontado por Bowden (2006), para quem, como não há equivalente global àquilo que o Estado representa em nível nacional, o escrutínio e a regulação da sociedade civil global são assaz comprometidos (essa consideração se liga à noção de uma governança sem governo, verificável em contextos que não possuem uma autoridade governamental central). Se isso, por um lado, favorece a maior liberdade da agência, por outro, cria um contexto de regras incapaz de posicionar um agente central responsável pelo julgamento e pela condenação dos demais a ele subordinados. $O$ autor percebe, ademais, já na literatura sobre a sociedade civil doméstica um quase consenso em torno do argumento defensor da existência de opostos em seu interior; isto é, qualquer visão lúdica e auspiciosa da sociedade civil como a solução dos males sociais foi há muito descartada, mesmo quando ainda nem se aludia à existência do nível global da sociedade civil.

Conforme dito anteriormente, enfatizar a dimensão global do termo não significa dizer que o local foi obliterado, que o Estado ruiu, que o universalismo imperou; conforme já foi exposto, a heterogeneidade da sociedade civil global é ampla, incorporando princípios e gerando efeitos dos mais distintos. Assim, quando se fala em "global", há a precaução de não entendê-lo em oposição ao "local" ou como sintoma da destruição do espaço interestatal e dos agentes estatais. A sociedade civil global não substitui a nacional, a doméstica, a regional ou de quaisquer outros níveis. Agentes do local podem absorver, conectar-se a ou rejeitar o global, podem nem mesmo estar em contato direto e/ou deliberado com ele. Em outros termos, remanescem os agentes não estatais de atuação simplesmente local ou nacional, não obstante, até para estes, a interconexão global esteja às portas, por um lado, disponível para ser explorada, reconstruída e manipulada; e, por outro, penetrante, impactando na atuação do local, a despeito das intenções dos agentes. A divisão ontológica, se naturalizada e reificada, fracassa em interpretar a complexidade do mundo contemporâ- 
neo; não que os níveis não existam enquanto realidade social, apenas não são ontologias definíveis ex ante. ${ }^{33}$ À noção de sociedade civil global é inerente a dimensão de tensão entre seus componentes; refutar uma visão unitária é muito mais do que reconhecer a existência de numerosos componentes; é não se esquivar do fato de serem difusos as demandas e os efeitos de poder gerados, de se estar diante de uma incontrolável multiplicidade, com focos de resistência às condições de governo da sociedade política, seja qual for o critério adotado para julgamento moral ou político dos modos de resistência.

O requisito para o entendimento da atuação dos agentes englobados pelo rótulo "sociedade civil global" é tornar os agentes não estatais de atuação global uma construção social por excelência, sem qualquer fração ontológica pré-social. ${ }^{34} \mathrm{O}$ processo de construção social não passa apenas por processos cognitivos e conscientes de apreensão e interpretação dos símbolos, dos sentidos e dos objetos e recursos físicos. Nesse aspecto, Kratochwil (1989) e Onuf (1989) tão somente sinalizam o que Ross (2006) e, em especial, a obra de Foucault propiciam: um congraçamento entre as dimensões conscientes e inconscientes dos processos de formação, reprodução e contestação entre os agentes na sociedade política. ${ }^{35} \mathrm{O}$ entendimento dos agentes da sociedade civil global requer a compreensão daquilo que os leva a agir e do que seus cursos de ação fazem ou podem fazer, intencionalmente ou não. Os aspectos afetivos e cognitivos caminham juntos, tanto nos modos de inserção e atuação dos agentes, como no que provocam naqueles que presenciam e interpretam suas manifestações sociais. $^{36}$

A sociedade civil global não transpõe o doméstico para o global. Rei$\tan$ (2007) ressalta a diferença contextual entre os níveis; no último, múltiplas formas de governo e aberturas políticas estão à disposição em um ambiente de recursos dispersos e dinâmicos. A ampliação e a contração da política formam um quadro de tensão intensificada na situação estratégica em que estão os agentes não estatais: alguns po- 


\section{Victor Coutinho Lage}

dem acabar absorvidos pelas condições de governo vigentes; outros podem permanecer na luta incessante contra elas, problematizando suas bases e seus efeitos, em defesa de uma mudança, porém sempre atuando a partir delas, e não como agentes que lhe sejam exteriores.

\section{Sociedade Civil Global como Espaço de Interação e Agentes Não Estatais}

Até o momento, o texto buscou, ao máximo, separar a discussão das duas partes da definição de sociedade civil global - na primeira, um espaço de inserção e atuação dos agentes não estatais; na segunda, o conjunto dos próprios agentes, concatenados sob um rótulo classificatório e problemático. Os esforços de separação das partes, entretanto, dão lugar, nesta seção, à tentativa de entender as duas partes em concomitância.

A sociedade civil global é, ao mesmo tempo, o espaço inserido na sociedade política e os agentes não estatais que ocupam esse espaço. A premência da inseparabilidade das duas partes resulta de tudo o que o termo suscita: como foi visto, ao longo da história, a ideia de sociedade civil esteve atada aos limites da autoridade política central e sempre denotava o espaço $e$ os agentes distintos do poder soberano, seja contrastando-os com as sociedades não civis externas, seja, posteriormente, com o Estado moderno. Com as simultâneas ampliação e contração da política, o "global" sinaliza uma nova concepção ontológica e política da sociedade política; o poder não é identificável como posse de algum agente, tampouco como propriedade transferível, e sim como táticas, estratégias, cadeias, redes de funcionamento normalizadoras e que permeiam as relações políticas e sociais entre agentes estatais e não estatais.

Uma objeção ao texto poderia se pautar na defesa de que a sociedade civil global seria, em sua acepção, um conceito incoerente em suas 
duas partes de definição: como espaço, careceria de um território em que as condições de governo seriam exercidas e resistidas; definida como agentes não estatais de escopo global, sofreria a inconsistência da inexistência de um "lugar" em que pudessem atuar. Ruggie (1998) refuta tal objeção: primeiro, condições de governo não requerem um território para se instaurar; mesmo se forem territoriais, de maneira alguma precisam ser territorialmente fixas. E mais: ainda que fossem fixas, não teriam de implicar a mútua exclusão. Os conceitos de sociedade política e de sociedade civil global, conforme trabalhados neste texto, convergem com essa formulação de condições de governo.

Chandhoke (2002) alerta que se deve ter cautela ao se abordar a concepção de sociedade civil global, seja como uma esfera autônoma, seja como uma alternativa às predominantes instituições sociais (Estados e corporações, por exemplo), ou na condição de crítica da ordem vigente. É crescente sua influência na opinião pública e nas políticas em diversos temas candentes nas relações sociais, desde as últimas décadas. Todavia, se a operação mais virtuosa dessa formulação conceitual está no sentido que atribui às experiências pessoais cotidianas, pode ocorrer um paradoxo quando se pensa em determinados membros da sociedade civil global (ONGs internacionais, por exemplo) que, antes de serem vias de iniciativa cidadã, são proponentes de agendas que falam em nome de e não com os seres humanos pelos quais alegam lutar, reproduzindo o tão discutido déficit democrático $^{37}$ que imputam às instituições contra as quais protestam (CHANDHOKE, 2002). Isso não é um atestado de óbito da sociedade civil global, e sim uma amostra de seus austeros desafios concernentes a representação e agência políticas e mesmo à própria definição da prática política (CHANDHOKE, 2002).

No relacionamento entre sociedade civil global e Estado, é preciso refletir sobre as influências da sociedade civil global sobre o comportamento do Estado, assim como sobre a consubstanciação de uma atividade política da sociedade civil global alheia ao sistema de Estados 


\section{Victor Coutinho Lage}

(RUGGIE, 2004) e, por fim, sobre a influência inversa - do Estado sobre a sociedade civil global. Essas três não exaustivas possibilidades indicam a multiplicidade dos espaços de interação imersos na sociedade política, tanto no âmbito interestatal quanto no âmbito exclusivo da sociedade civil global e no de interação dos dois anteriores. A sociedade civil global - espaço e agentes - expressa os limites das condições de governo e, como destaca Kratochwil (2001), a inexorável coexistência de padrões de integração e de afirmações de particularidades na dinâmica política.

Quando se fala aqui em resistência, conflito, contestação e mudança, não se está alinhado a uma abordagem voltada à comunicação como forma de atingir o consenso. Na obra de Foucault, a metáfora da guerra pode ser interpretada em seu papel de não deixar os agentes se esquecerem, por um lado, de sua capacidade e de sua responsabilidade pela construção social da realidade e, por outro, dos efeitos de poder ao qual são submetidos e os quais ajudam a reproduzir (DREYFUS; RABINOW, 1995; BIEBRICHER, 2005). Da mesma forma, não se pode negligenciar que a própria tentativa de definição de um termo, como aqui se procede, é um ato político, imerso em condições de governo e seus padrões de inclusão e exclusão, de distribuição desigual de benefícios e privilégios. Talvez estejam nisso os limites e as possibilidades de toda abordagem que renegue o princípio de neutralidade axiológica. À medida que se defende a produção de conhecimento como ato político, depara-se com uma problemática fundamental: a estipulação de critérios de julgamento. Em razão do escopo desse texto, é impensável o engajamento nessa problemática. Por ora, basta defender que a sociedade civil global representa um espaço e um conjunto de agentes não estatais, os quais, por seu turno, reconstituem constantemente o próprio espaço em que emergem e, por conseguinte, a sociedade política. O impacto que gerará, o modo como deve ser regulado, o critério a ser estipulado são aspectos inerentes às relações sociais e políticas. Ruggie (1998), sobre a mudança social, define três 
aspectos: consequências não antecipadas incidem nos resultados de longo prazo; as transformações fundamentais, cujas origens podem remontar a períodos longínquos, advêm em momentos de crise nem sempre tão longos e de maneira nem sempre tão lenta; por fim, nunca é plena e totalizante. Se há consequências não antecipadas, é ilusório antever a trajetória específica a ser percorrida; se as transformações fundamentais não são tão lentas, torna-se mais motivador lutar por elas; por fim, se nunca é plena a mudança, sempre haverá interstícios e focos de resistência.

\section{Conclusão}

A força interpretativa da definição de sociedade civil global incide diretamente no campo de Relações Internacionais, há muito vinculada ao discurso canônico da anarquia e da centralidade do Estado: se esses agentes não estatais não conduzem necessariamente a uma transcendência sistêmica, é indiscutível, no entanto, que apresentam desafios à dicotomia anarquia/soberania, conforme a qual o Estado representa a presença soberana imutável, e o internacional, o resíduo negativo anárquico (ASHLEY, 1988).

Corry (2006) aponta três formas de críticas correntes à noção de sociedade civil global. Voltar-se-iam elas contra: a ambiguidade do conceito, a sua incapacidade de reconfigurar ou transformar as premissas de centralidade do Estado contra as quais supostamente se erige e os traços não democráticos que lhe seriam inerentes. Encontram-se, no mesmo autor e ao longo das seções anteriores, respostas que parecem satisfatórias: o primeiro tipo de crítica é de impacto limitado, haja vista a já constatada natureza contestável dos conceitos em ciências sociais. A ambiguidade de um conceito, antes de um problema a ser resolvido, é condição intrínseca de seu caráter histórico, social e político. No que diz respeito à segunda crítica, o conceito de sociedade civil global não pode ser pensado abstraído de sua própria história (com suas vicissitudes e estabilizações), inseparável do Estado. 


\section{Victor Coutinho Lage}

Como foi enfatizado, esse termo não pretende substituir o espaço interestatal, condenar à morte o Estado ou decretar o fim de sua influência na dinâmica social. O que ele sinaliza é uma nova relação entre espaço, Estado e política (NOGUEIRA, 2000). Nas palavras de Foucault: "Eu não pretendo, de maneira alguma, minimizar a importância e a efetividade do poder do Estado. Sinto apenas que a excessiva insistência em seu papel exclusivo conduz ao risco de omitir todos os mecanismos e efeitos do poder que não passam diretamente pelos aparatos estatais" (FOUCAULT apud MAY, 2005, p. 75). ${ }^{38}$

Finalmente, com referência ao último formato crítico, expôs-se, acima, o desafio de construção de responsividade e legitimidade na sociedade civil global. Se bem que seja indispensável reconhecer a conturbada relação entre esta e a democracia, ${ }^{39}$ o questionamento não pode ser conduzido pelo argumento de serem incoerentes e fadadas ao insucesso quaisquer tentativas de estabelecimento de legitimidade fora das fronteiras do Estado. Um entendimento de democracia não como fruto de um governo com autoridade hierárquica central, e sim como gerenciável por uma governança interagencial poderia representar o primeiro passo para o enfrentamento do desafio acima. Vale lembrar que a sociedade civil global não é nem democrática, nem tampouco não democrática por definição, porém pode ser uma e/ou outra, dependendo das vias pelas quais opta.

Nesse contexto, as perspectivas acerca da sociedade civil global, expressas, por exemplo, na literatura com a qual se engaja este texto, possuem uma dupla função: constituir o global como um espaço político e torná-lo hospitaleiro a modos de governo diferentes da soberania estatal centralizada (BARTELSON, 2006). É prematuro estipular um elo entre uma promessa de transcendência sistêmica e a sociedade civil global (BARTELSON, 2006); contudo, de fato esse novo espaço e esses novos agentes tornam a separação entre as esferas doméstica e internacional menos capaz de interpretar a realidade social. Um traço expresso pelo conceito de sociedade civil global é o 
dinamismo, marcado por contestação, inovação, conflito, cooperação e autorreflexão, advindo tanto dos agentes dessa sociedade, como de seus estudiosos (KEANE, 2001), e que confirma a "vida" do conceito como elemento constitutivo não somente do mundo, como também da identidade dos agentes e, por conseguinte, da forma como operam no espaço.

A definição proposta nesse texto almejou evitar as mazelas do presentismo e da inflação conceitual, a reprodução de oposições ontológicas cristalizadas e a ligação direta entre o conceito trabalhado e algum tipo de futuro teleológico ou de fim da história. O diálogo entre o construtivismo e Foucault contribui para (1) o entendimento das características políticas e de poder da realidade social; (2) a constituição e a organização dessa própria realidade; e (3) a função de mudança social ou contestação normativa que pode suscitar.

Em consonância com Onuf, Guzzini e Foucault, os agentes por todo o tempo serão constituídos por condições de governo; porém, também constituirão essas condições, de acordo com suas capacidades de agência e com sua postura crítica e problematizadora diante da realidade social em que vivem. Essa interação entre agentes e instituições ocorre em um contexto político ampliado - no número de agentes e nas possibilidades de intervenção - e contraído - pelas regras constitutivas dos sujeitos, dos espaços e das próprias liberdades de atuação e/ou resistência. Esta parece ser a dinâmica da sociedade política.

\section{Notas}

1. Os três rótulos acima são objetos de discussão e divergência intensas entre estudiosos. Para o propósito deste texto, basta que se volte a eles como expressões da variedade de alternativas (meta)teóricas que floresceram nas ciências 


\section{Victor Coutinho Lage}

sociais a partir da segunda metade do século XX, não cabendo, portanto, a análise dos termos.

2. É provável que a primeira ocorrência do termo "sociedade civil global" em jornais internacionais de grande circulação tenha sido somente em 1991 (CORRY, 2006).

3. O construtivismo é uma abordagem multifacetada e, em muitos casos, testemunha uma divergência interna considerável. $O$ artigo lida com a vertente construtivista orientada por regras ou linguística, cujos precursores são Nicholas Onuf (1989) e Friedrich Kratochwil (1989).

4. No original, "conceptual inflation" (MUNCK, 2002, p. 352).

5. O "cosmopolitismo liberal ingênuo" caracterizar-se-ia em abordagens, como a de David Held, que preconizassem a formação ou a consolidação de um estágio comunitário democrático global que dirimisse o totalitarismo ou quaisquer modelos que contradissessem a democracia cosmopolita.

6. No original, "a discourse the the [sic] anarchy problematique" (ASHLEY, 1988, p. 227).

7. Hall (1992) entende lugar como algo limitado, específico, concreto, familiar.

8. Vale mencionar aqui o historiador Reinhart Koselleck, que dedicou grande parte de sua obra ao questionamento da importância da história de um conceito. Ver, por exemplo, Koselleck (2002, 2004).

9. A relação agente-estrutura teve uma de suas formulações pioneiras na obra The constitution of society, de Giddens (1984). É dela, ainda, que este artigo toma de empréstimo a noção de agência, entendida como a capacidade de exercer algum tipo de poder na sociedade: um agente é, por definição, um indivíduo, entretanto há a tendência, não rejeitada por Giddens (1984), de se atribuir agência a coletividades.

10. Para a constatação detalhada e quantitativa da diversidade das entidades da sociedade civil global, ver Salomon et al. (2003).

11. De maneira sumária, ontologia se refere à natureza do ser, da realidade ou do ente a ser estudado. Na filosofia, é um termo em torno do qual gira uma histórica controvérsia, cujas expressões mais recentes podem ser lidas em Martin Heidegger e Jacques Derrida, entre outros.

12. $O$ escopo deste texto não permite a discussão acerca das controvérsias acerca do rótulo "construtivismo" em Relações Internacionais. Para alguns exemplos de tais disputas, ver Guzzini (2000) e os textos compilados a partir de 

INTERNATIONAL STUDIES, 2001).

13. A palavra rule apresenta muitas traduções possíveis, como "dominação", "regra", "governo". Opta-se aqui por "governo", entendendo que tal termo possibilita a concepção de uma sociedade constituída por regras que distribuem privilégios e benefícios de maneira desigual, podendo levar a condutas de dominação entre os agentes, porém não se restringindo a elas. Outro motivo dessa escolha é a abertura para problematizar a separação entre o ambiente interno (doméstico), em que haveria "governo", e o externo (internacional), em que o governo estaria ausente dada a inexistência de uma autoridade central hierárquica. A expressão "condições de governo" busca questionar tal distinção ontológica.

14. O construtivismo aqui adotado defende que: um ato de fala, proferido pelo agente, pode se transformar em regra e esta em instituição, em um processo de constituição de condições de governo diferentes; em concomitância, essas condições fornecem os contextos de interação nos quais os agentes estarão inseridos e proferirão seus atos de fala, com intenção de institucionalizá-los ou, ao menos, de torná-los regras sociais. Seus precursores e principais expoentes são Onuf (1989) e Kratochwil (1989).

15. Kratochwil (1989) e Wendt (1999) são outros exemplos da fração da literatura construtivista a não se imiscuir na problemática do poder nas relações sociais.

16. Após a conclusão da escrita deste artigo, textos recentes de Onuf lidaram com a noção de "poder", embora de uma forma que se distancia da que aqui se discute. Parte dos desenvolvimentos recentes do "construtivismo" de Onuf será publicada em breve em um livro que compila alguns de seus artigos recentes (ONUF, [no prelo]). O autor agradece a Onuf pelo acesso ao livro e pelas inúmeras discussões acerca do "construtivismo" em Relações Internacionais, entre outros assuntos.

17. Em outras palavras, o conceito de poder é essencial para o estabelecimento da relação entre a construção social da realidade (ação) e a construção social do conhecimento (observação) (GUZZINI, 2000).

18. Se as duas últimas são em larga medida compartilhadas pelos demais construtivistas, a primeira é pouco ou nada trabalhada por grande parte deles.

19. Uma discussão profunda e complexa das bases filosóficas do construtivismo conduziria o texto a autores como o segundo Ludwig Wittgenstein, Jurgen Habermas, Anthony Giddens e John Searle. O escopo deste texto não permite a incursão nessa literatura, no entanto. 


\section{Victor Coutinho Lage}

20. No original: “To be 'political' means to be potentially changeable; i.e., not something natural, God-given, but something which has the potential to be influenced by agency" (GUZZINI, 2005, p. 511).

21. Conforme Kratochwil (2006), a predefinição dos fatores conducentes a um resultado legítimo é impossível, dado que a legitimidade é, eminentemente, social e compartilhada, desempenhando um papel crucial no discurso e na prática políticos. O uso do termo "intersubjetivo" é frequente na literatura construtivista e, por vezes, é intercambiado com "social" ou "socialmente compartilhado". Entretanto, tal intercâmbio se mostra problemático sob uma perspectiva de história intelectual, por razões que escapam ao escopo deste texto. Sendo assim, opta-se pelo uso de "construção social", não "intersubjetiva".

22. No original: "understand power as both agencial and intersubjective (including non-intentional and impersonal power) [...] more attuned to questions of open or taken-for-granted and "naturalised' legitimation processes" (GUZZINI, 2005, p. 507-508).

23. Foucault e o construtivismo não representam, por óbvio, um pioneirismo na relação entre poder e política. Entretanto, o diálogo entre ambos pode contribuir para um novo entendimento da política, do poder e da relação entre estes.

24. O foco deste texto é nos escritos de Foucault iniciados na década de 1970, quando o pensador trabalhou de forma mais explícita a noção de poder. No presente texto, não serão possíveis uma discussão aprofundada da obra do autor e um contraste pormenorizado entre o mesmo e o construtivismo; destarte, o objetivo é construir um Foucault que auxilie o construtivismo desenhado acima.

25. Segundo May (2005), este seria um autodeclarado otimismo de Foucault. Vale lembrar, porém, que a concepção de resistência em Foucault não é necessariamente associada a uma ação consciente e deliberada do agente, tampouco a uma teleologia progressista das relações sociais.

26. Entre as interpretações de Foucault, duas são destacáveis: a do "Foucault americano", compromissada com princípios liberais, busca no autor uma estratégia que leve os indivíduos à liberdade, ao descolamento da condição de dominação (MAY, 2005; FILLION, 2004); a do "Foucault francês", por seu turno, nega a possibilidade de ver na obra do autor traços explícitos de um futuro livre ou a profusão de morais práticas e políticas, afinal a dominação é uma situação estratégica perene, daí a intenção do autor ser apenas um estímulo a inquietações diante dos efeitos do poder (CUSSET, 2008). A abordagem do presente texto se aproxima, nesse sentido, do "Foucault francês".

27. "Recursos", tanto para o construtivismo quanto para Foucault, podem ser entendidos à luz de Giddens (1984), isto é, seja como recursos alocáveis (com 


\section{"Sociedade Civil Global": Agentes Não Estatais e Espaço de Interação na Sociedade...}

uma materialidade identificável, como matérias-primas, finanças, entre outros), seja como recursos de autoridade (os quais atribuem uma capacidade de comando entre pessoas ou agentes).

28. No original, "think and act globally" (RUGGIE, 2004, p. 510).

29. No original: "The end of the Cold War and growing interconnectedness have undermined the territorial distinction between 'civil' and 'uncivil' societies, between the 'democratic' West and the 'non-democractic' East and South, and have called into question the traditional centralized war-making state" (KALDOR, 2003, p. 2).

30. Recentemente, a controvérsia acerca da noção do "global" em Relações Internacionais ganhou novo ímpeto com algumas intervenções de R. B. J. Walker e com a retomada das críticas a abordagens cosmopolitas. Para alguns exemplos dessa discussão, ver Walker (2010) e algumas críticas ao livro no volume 10, número 2, 2011, do periódico Contemporary Political Theory. Esse debate não pode ser contemplado neste texto, escrito em 2009.

31. Bartelson (2006) apresenta três explicações para os motivos pelos quais emergiu a distinção entre sociedade civil e autoridade governamental.

32. Ver, ainda, Bartelson (2009).

33. Wight (2006) enseja a discussão pormenorizada da relação entre ontologia e níveis de análise nas ciências sociais e nas Relações Internacionais, propondo a separação estrita entre o problema ontológico (relação agente-estrutura) e o problema metodológico e epistemológico (níveis de análise), partindo de uma perspectiva que denomina como "realismo científico" e que vem suscitando controvérsias desde o início dos anos 2000 em Relações Internacionais. Para alguns debates em torno do "realismo científico", ver também o volume 10, número 3, 2007, do periódico Journal of International Relations and Development e o volume 38, 2012, do periódico Review of International Studies.

34. Mesmo porque, caso se assumisse alguma dimensão pré-social, ou se estaria cristalizando outra dicotomia ontológica e política (em que o global seria um espaço posterior de atuação dos agentes, cujas identidades, portanto, já teriam sido parcialmente construídas em um nível anterior, local ou nacional, por exemplo), ou se adotaria uma concepção ontológica dividida do agente, cuja parte não seria suscetível de mudança social.

35. Em Vigiar e punir, Foucault (1987) narra como a aplicação de penalidades fazia florescer emoções nos expectadores e, com isso, conduzi-los a protestos, a resistências e à mudança social. 


\section{Victor Coutinho Lage}

36. Nesse sentido, os ataques de 11 de setembro podem ser interpretados como tendo sido conduzidos por agentes da sociedade civil global cujas identidades se constroem não somente como fruto de reflexões conscientes acerca de suas necessidades no mundo contemporâneo, como também como resultado de sua vinculação a emoções advindas de convicções religiosas e fundamentalistas aderidas por processos por vezes inconscientes. Ademais, o atentado provocou uma reação popular cognitiva e interpretativa e, em larga medida, emocional, o que se atesta nos discursos sobre os eventos, sempre mesclando o apelo ao modo "racional" de enfrentamento da situação e aos valores históricos nacionais a serem defendidos. Ver Ross (2006).

37. "Déficit democrático" se reporta à situação de negociadores e tomadores de decisão em ambiente supranacional ou internacional não serem, em muitos casos, políticos eleitos pelas suas respectivas constituintes nacionais, malgrado a influência direta que suas deliberações geram na vida das populações dos Estados. A União Europeia e o Fundo Monetário Internacional são alguns exemplos de instituições acusadas de gerarem déficit democrático.

38. No original: "I do not mean in any way to minimize the importance and effectiveness of State power. I simply feel that excessive insistence on its playing an exclusive role leads to the risk of overlooking al the mechanisms and effects of power which don't pass directly via the State apparatus" (FOUCAULT apud MAY, 2005, p. 75).

39. Talvez o ponto central da relação entre sociedade civil global e democracia se edifique na ausência de controle democrático da primeira, haja vista a ausência de mecanismos aptos para tanto no espaço de interação por ela aberto. Responsividade (accountability) - ou a ausência dela - é conceito que resume bem o que há de conturbado nessa relação. Por exemplo, ver Kaldor et al. (2005).

\section{Referências Bibliográficas}

ASHLEY, Richard. Untying sovereign State: a double reading of the anarchy problematique. Millenium, v. 17, n. 2, p. 227-262, 1988. 
ATAMAN, Muhittin. The impact of non-State actors on world politics: a challenge to Nation-States. Alternatives: Turkish Journal of International Relations, v. 2, n. 1, p. 42-66, 2003.

AXFORD, Barrie. Global civil society or "networked globality": beyond the territorialist and societalist paradigm. Globalizations, v. 1, n. 2, p. 249-264, 2004.

BAKER, Gideon. Problems in the theorization of global civil society. Political Studies, v. 50, p. 928-943, 2002.

BARTELSON, Jens. Three concepts of globalization. International Sociology, v. 15, n. 2, p. 180-196, 2000.

Making sense of global civil society. European Journal of International Relations, v. 12, n. 3, p. 371-395, 2006.

BARTELSON, Jens. Visions of World Community. Cambridge: Cambridge University Press, 2009.

BIEBRICHER, Thomas. Habermas, Foucault and Nietzsche: a doublé misunderstanding. Foucault Studies, n. 3, p. 1-26, 2005.

BOWDEN, Brett. Civil society, the State, and the limits to global civil society. Global Society, v. 20, n. 2, 2006.

CHANDHOKE, Neera. The limits of global civil society. In: GLASIUS, M. et al. (Ed.). Global civil society: yearbook 2002. Nova Iorque: Oxford University Press, 2002. p. 35-53.

COHEN, Jean L. Sociedade civil e globalização: repensando categorias. Dados: Revista de Ciências Sociais, v. 46, n. 3, p. 419-459, 2003.

CORRY, T Olaf. Global civil society and its discontents. Voluntas, n. 17, p. 303-324, 2006.

CUSSET, François. French theory: how Foucault, Derrida, Deleuze, \& Co. Transformed the intellectual life of the United States. Minneapolis: University of Minnesota Press, 2008.

DREYFUS, Hubert L.; RABINOW, Paul. Michel Foucault: uma trajetória filosófica - para além do estruturalismo e da hermenêutica. Rio de Janeiro: Forense Universitária, 1995. 


\section{Victor Coutinho Lage}

FILLION, Réal. Freedom, responsability, and the "American Foucault". Philosophy \& Social Criticism, v. 30, n. 1, p. 115-126, 2004.

FLYVBJERG, Bent. Habermas and Foucault: thinkers for civil society? British Journal of Sociology, v. 49, n. 2, p. 210-233, 1998.

FOUCAULT, Michel. The subject and power. Critical Inquiry, v. 8, n. 4, p. 777-795, 1982.

Vigiar e punir: história da violência nas prisões. 32. ed. Petrópolis: Editora Vozes, 1987.

_ Em defesa da sociedade. São Paulo: Martins Fontes, 2005.

_. Microfísica do poder. 24. ed. Rio de Janeiro: Edições Graal, 2007a.

. The politics of truth. Los Angeles: Semiotext(e), $2007 \mathrm{~b}$.

GIDDENS, Anthony. The constitution of society. Los Angeles: University of California Press, 1984.

As consequências da modernidade. São Paulo: Editora Unesp, 1991.

GUZZINI, Stefano. A reconstruction of constructivism in International Relations. European Journal of International Relations, v. 6, n. 2, p. 147-182, 2000.

Constructivism and the role of institutions in International Relations. Copenhague: Copenhagen Peace Research Institute, 2003. p. 1-23.

The concept of power: a constructivist analysis. Millennium: Journal of International Studies, v. 33, n. 3, p. 495-521, 2005.

HABERMAS, Jurgen. O discurso filosófico da modernidade. São Paulo: Martins Fontes, 2002a.

Pensamento pós-metafísico. 2. ed. Rio de Janeiro: Tempo Universitário, $2002 b$.

HALL, Stuart. The question of cultural identity. In: HALL, S. et al. (Ed.). Modernity and its futures. Cambridge: Polity Press, 1992. p. 273-326.

KALDOR, Mary. Global civil society: an answer to war. Cambridge: Polity Press, 2003. 
; ANHEIER, Helmut; GLASIUS, Marlies. Introduction. In: ANHEIER, H. et al. (Ed.). Global civil society: yearbook 2004/5. Londres: Sage Publications Ltd., 2005. p. 1-22.

KEANE, John. Global civil society? In: ANHEIER, H. et al. (Ed.). Global civil society: yearbook 2001. Nova Iorque: Oxford University Press, 2001. p. 23-47.

KELLNER, Douglas. Critical theory and the crisis of social theory. Sociological Perspectives, v. 33, n. 1, p. 11-33, 1990.

KOSELLECK, Reinhart. The practice of conceptual history: timing history, spacing concepts. Stanford: Stanford University Press, 2002.

Futures past: on the semantics of historical time. Nova Iorque: Columbia University Press, 2004.

KRATOCHWIL, Friedrich V. Rules, norms and decisions: on the conditions of practical and legal reasoning in International Relations and domestic affairs. Cambridge: Cambridge University Press, 1989.

The politics of place and origin: an enquiry into the changing boundaries of representation, citizenship and legitimacy. International Relations of Asia-Pacific, v. 1, p. 143-165, 2001.

On legitimacy. International Relations, v. 20, n. 3, p. 302-308, 2006.

LAGE, Victor Coutinho. Política: produção de fronteiras, limites e subjetividades. 2011. Dissertação (Mestrado em Relações Internacionais) - Pontifícia Universidade Católica do Rio de Janeiro, 2011. Disponível em: <http://www2.dbd. puc-rio.br/pergamum/biblioteca $/ \mathrm{php} / \mathrm{mostrateses} . \mathrm{php}$ ?open $=1 \&$ arqtese $=$ 0912321_11_Indice.html>. Acesso em : 17 out. 2011.

MAY, Todd. Foucault now? Foucault Studies, n. 3, p. 65-76, 2005.

MUNCK, Ronaldo. Global civil society: myths and prospects. International Journal of Voluntary and Nonprofit Organizations, v. 13, n. 4, p. 349-361, 2002 .

Global civil society: royal road or slippery path? Voluntas, n. 17, p. 325-332, 2006.

NOGUEIRA, João Pontes. Notas sobre a contribuição da teoria crítica à problematização do espaço nas Relações Internacionais. Contexto Internacional, v. 22, n. 2, p. 353-380, 2000. 


\section{Victor Coutinho Lage}

ONUF, Nicholas Greenwood. World of our making: rules and rule in social theory and International Relations. Columbia: University of South California Press, 1989.

Making sense, making worlds: constructivism in social theory and International Relations. Londres: Routledge, [no prelo].

REITAN, Ruth. A global civil society in a world polity, or angels and nomads against empire? Global Governance, n. 13, p. 445-460, 2007.

ROSS, Andrew A. G. Coming in from the cold: constructivism and emotions. European Journal of International Relations, v. 12, n. 2, p. 197-222, 2006.

RUGGIE, John Gerard. Constructing the world polity: essays on international institutionalization. Londres: Routledge, 1998.

Reconstituting the global public domain: issues, actors, and practices. European Journal of International Relations, v. 10, n. 4, p. 499-531, 2004.

SALOMON, Lester M.; SOKOLOWSKI, Wojciech; LIST, Regina. Global civil society: an overview. Baltimore: The John Hopkins University, 2003.

SCHOLTE, Jan Aart. Defining globalization. In: SCHOLTE, J. A. Globalization: a critical introduction. Nova Iorque: Palgrave Macmillan, 2005. p. 49-84.

SEARLE, John. The construction of social reality. Londres: Penguin Books, 1995.

WALTZ, Kenneth N. Teoria das Relações Internacionais. Lisboa: Gradiva, 2002.

WALKER, R. B. J. Inside/outside: International Relations as political theory. Cambridge: Cambridge University Press, 1993.

After the Globe, Before the World. Londres: Routledge, 2010.

WENDT, Alexander. Social theory of international politics. Cambridge: Cambridge University Press, 1999.

WIGHT, Colin. Agents, structures, and International Relations. Polities as ontology. Cambridge: Cambridge University Press, 2006. 

ting constructivist International Relations research. Los Angeles: University of Southern California, out. 2001.

YUNKER, James A. Effective global governance without effective global government: a contemporary myth. World Futures, n. 60, p. 503-533, 2004.

\section{Resumo}

\section{"Sociedade Civil Global": Agentes Não Estatais e Espaço de Interação na Sociedade Política}

O presente artigo visa compreender o conceito de sociedade civil global, a partir de um diálogo entre o construtivismo em Relações Internacionais e o pensador francês Michel Foucault. Dividido em três seções seguidas por uma conclusão, o texto almeja inserir-se em um espaço acadêmico de profunda contestação das bases filosóficas que permeiam as teorias convencionais nas ciências sociais e, em especial, nas Relações Internacionais. A primeira seção dedica-se à discussão acerca da sociedade civil global como espaço de interação agente-estrutura; na seção subsequente, ao conceito como um conjunto heterogêneo de agentes não estatais de escopo global. A terceira seção funde as duas partes da definição. Assim, propõem-se duas dimensões definidoras da sociedade civil global: na primeira, como espaço político; na segunda, como conjunto de agentes de características específicas. Por fim, uma breve conclusão encerra o texto - mas não a polêmica da discussão. Conclui-se que o contexto contemporâneo é marcado por uma complexidade de tal magnitude que torna urgente uma abordagem que evite oposições binárias e fronteiras ontológicas naturalizadas e reificadas, estando, assim, apta a interpretar de maneira mais adequada as relações sociais e políticas atuais.

Palavras-chave: Sociedade Civil Global - Construtivismo - Foucault - Sociedade Política 


\section{Abstract}

\section{"Global Civil Society": Non-state Agents and Space of Interaction in Political Society}

This article aims at understanding the concept of global civil society, from a dialogue between constructivism in International Relations and the French thinker Michel Foucault. Divided in three sections, followed by a conclusion, the text intends to insert itself in an academic space of a profound contestation concerning the philosophical basis of the conventional theories in the social sciences and, specially, in International Relations. The first section is dedicated to the discussion about global civil society as a space of agent-structure interaction; the next section treats the concept as a heterogeneous set of non-state agents of global scope. The third section fuses the two parts of the definition. This way, two defining dimensions of global civil society are proposed: in the first one, a political space; in the second, a set of agents with specific characteristics. Lastly, a brief conclusion ends the text - but not the polemics involved in the discussion. It's concluded that the contemporary context is marked by a huge complexity, so that it becomes urgent an approach that precludes binary oppositions, and naturalized and reified ontological boundaries, thus being able to interpret in a more adequate way the actual social and political relations.

Keywords: Global Civil Society - Constructivism - Foucault - Political Society 